\title{
Sexual dimorphism in prostacyclin-mimetic responses of rat mesenteric and coronary arteries.
}

\author{
Samuel Baldwin ${ }^{1}$, Elizabeth Forrester ${ }^{1}$, Lauren McEwan ${ }^{1}$, and Iain Greenwood ${ }^{1}$ \\ ${ }^{1}$ St George's University of London
}

April 26, 2021

\begin{abstract}
Background and purpose- Prostacyclin mimetics are widely used clinically. As such it is pertinent to understand the mechanisms underlying the vasoactive response to such agents, yet to date, no study has considered sex as a factor. The aim of this study was to characterise the effect of prostacyclin mimetics, Iloprost and MRE-269, on precontracted arterial tone from male and female Wistar arteries. As a secondary consideration, we investigated Kcnq-encoded KV7 channels as potential downstream targets of prostacyclin-IP-receptor mediated signalling. Experimental approach- Relative mRNA transcript and protein abundance were determined by RT-qPCR and immunocytochemistry respectively. The effect of Iloprost and MRE-269 was determined on pre-contracted arterial tone in the presence of pharmacological modulators of potassium channels and molecular interreference of KV7.1 within 2nd order mesenteric and left anterior descending arteries from male and female Wistar rats. Key resultsIloprost evoked a bi-phasic response in male mesenteric arteries, at low concentrations relaxing, then contracting the vessel at high concentration in a process attributed to IP and EP3 receptors respectively. Secondary contraction was absent in the females, potentially underpinned by a reduction in Ptger3. Pharmacological inhibition and molecular interference of KV7.1 significantly attenuated MRE-269 mediated relaxation in male and female Wistar in Diestrus / Metoestrous, but not Pro-oestrus / Oestrus. Conclusions and implications- Stark sexual dimorphisms in Iloprost mediated vasoactive responses are present within mesenteric arteries. KV7.1 is implicated in IP-receptor mediated vasorelaxation and is impaired by the Oestrus cycle.
\end{abstract}

\section{Hosted file}

Baldwin 2021- PC paper- BJP format.pdf available at https://authorea.com/users/326861/ articles/519512-sexual-dimorphism-in-prostacyclin-mimetic-responses-of-rat-mesentericand-coronary-arteries 


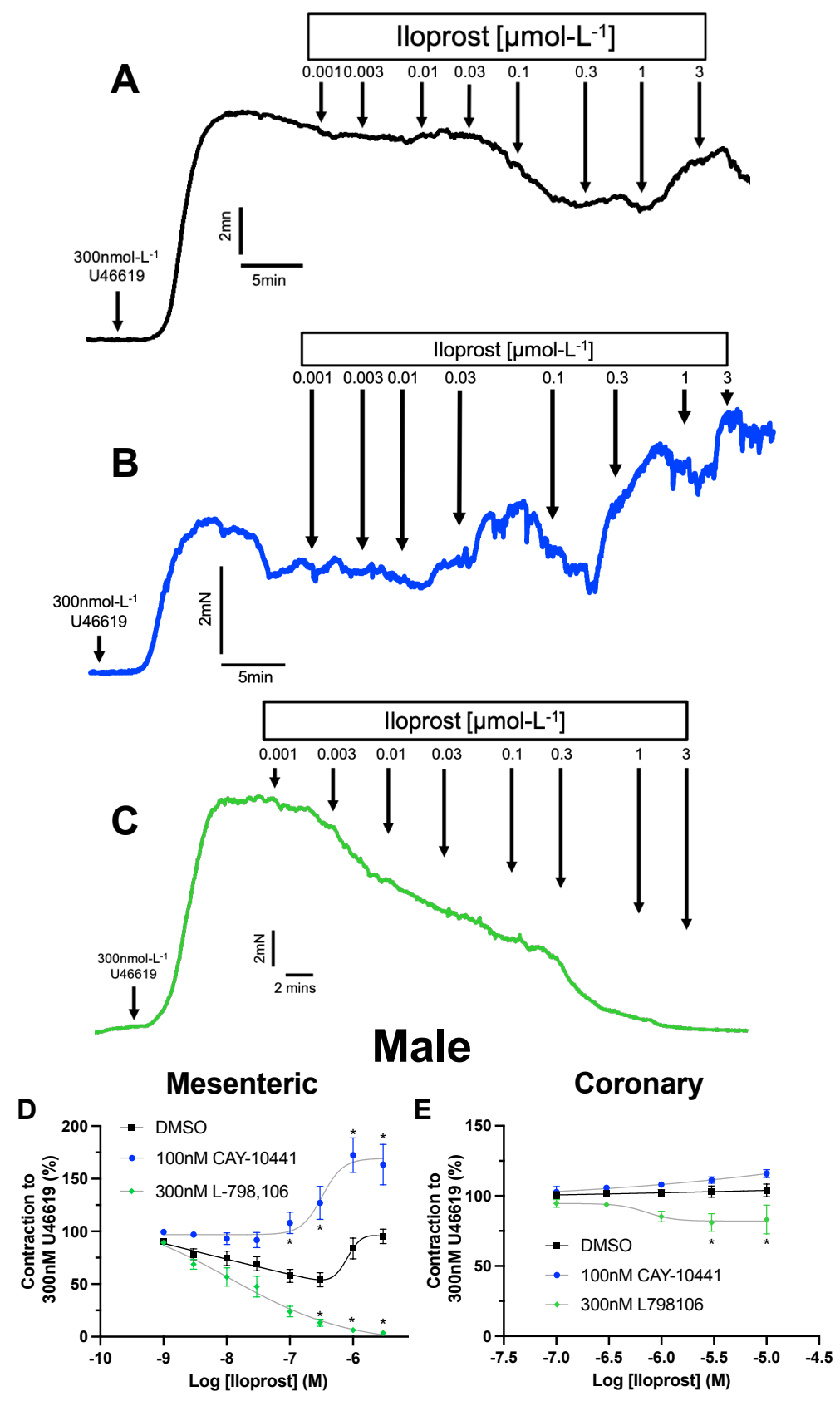




\section{Female}

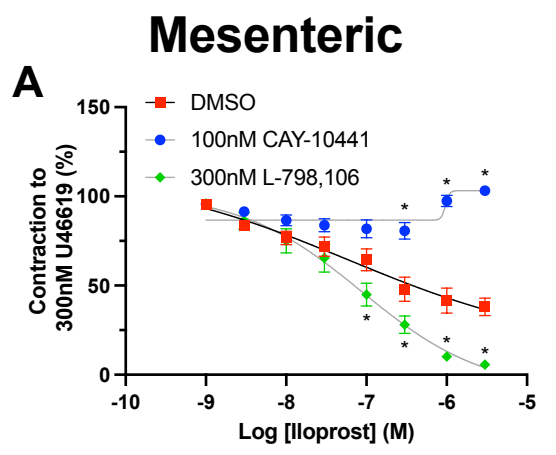

\section{Coronary}
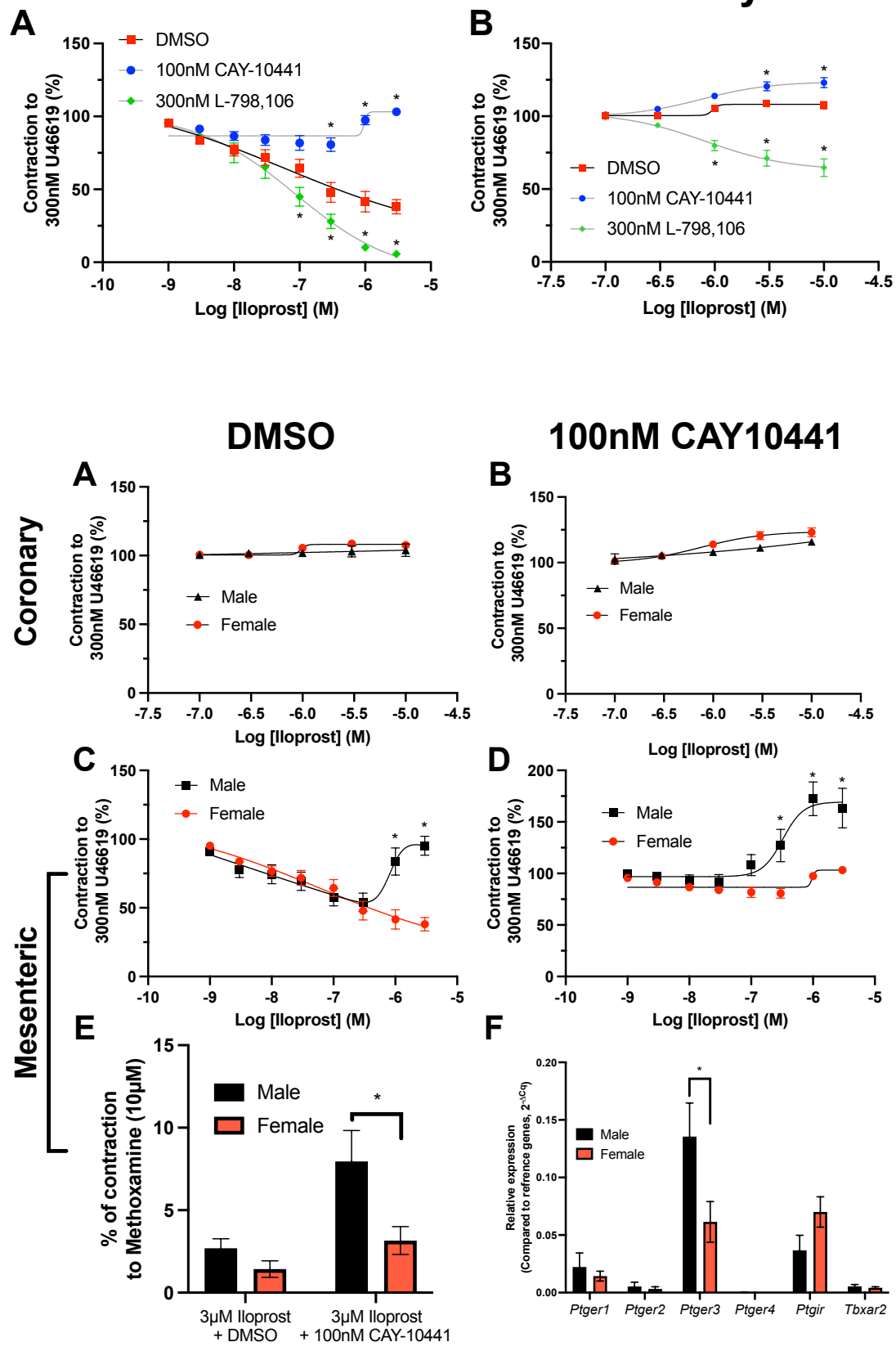

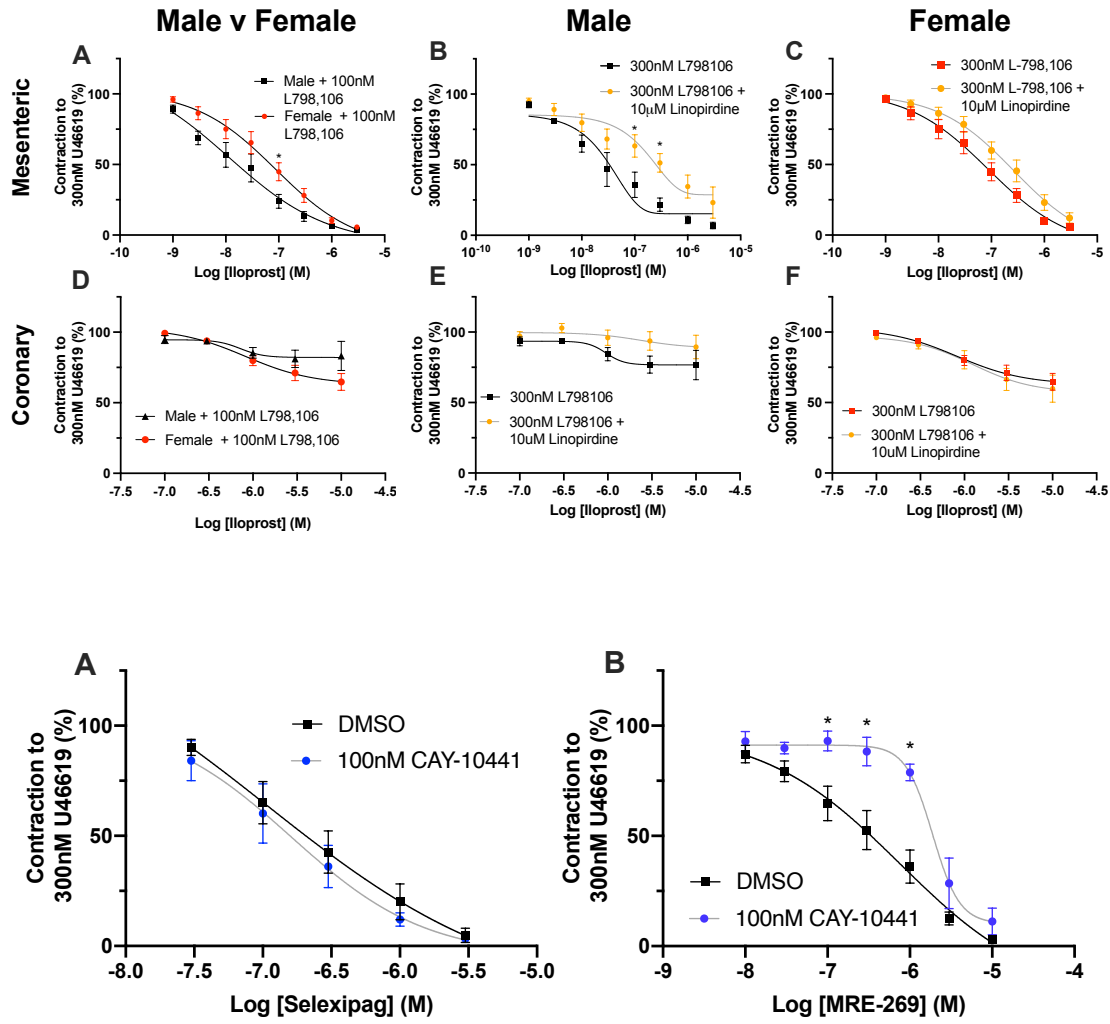

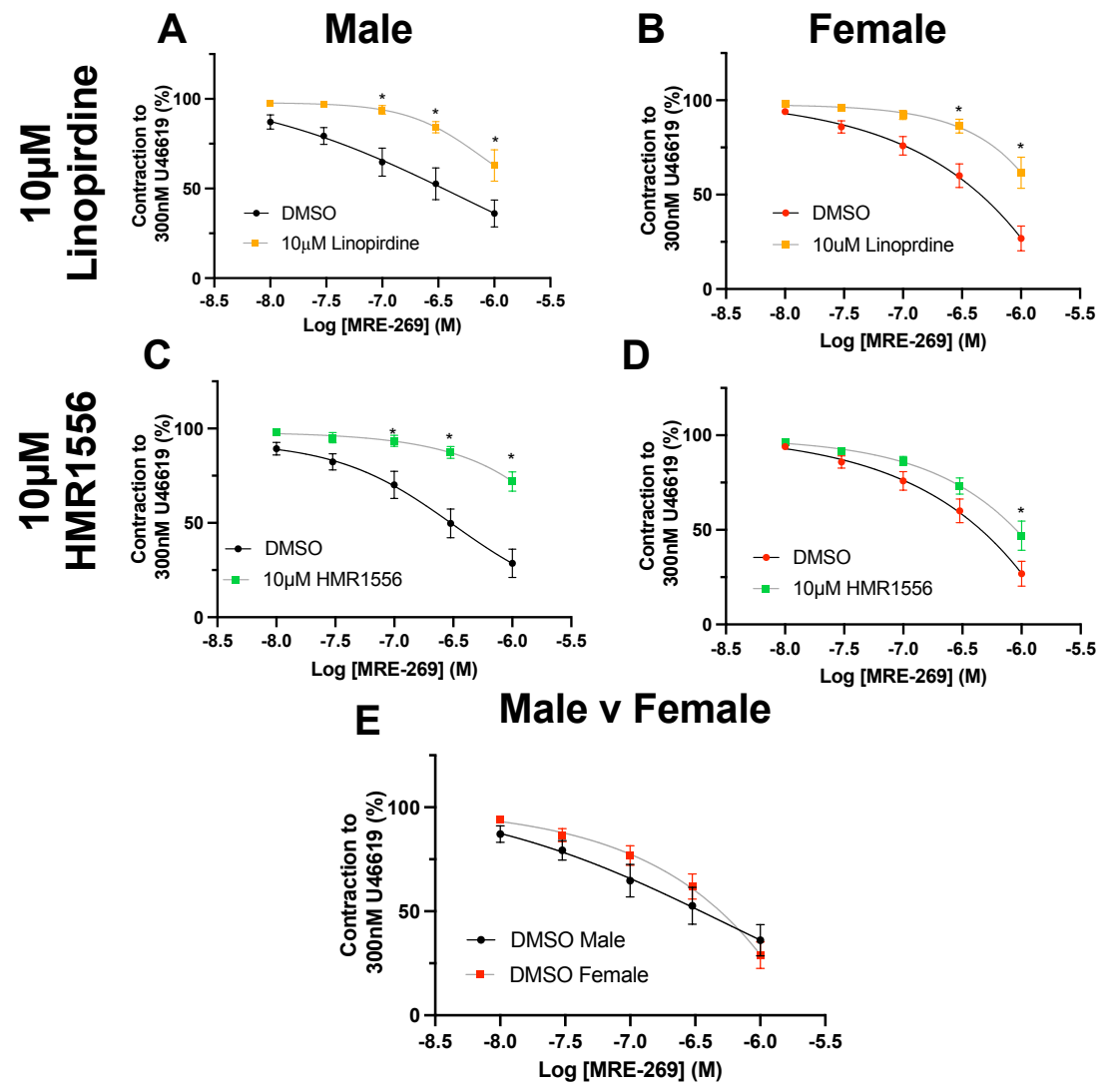


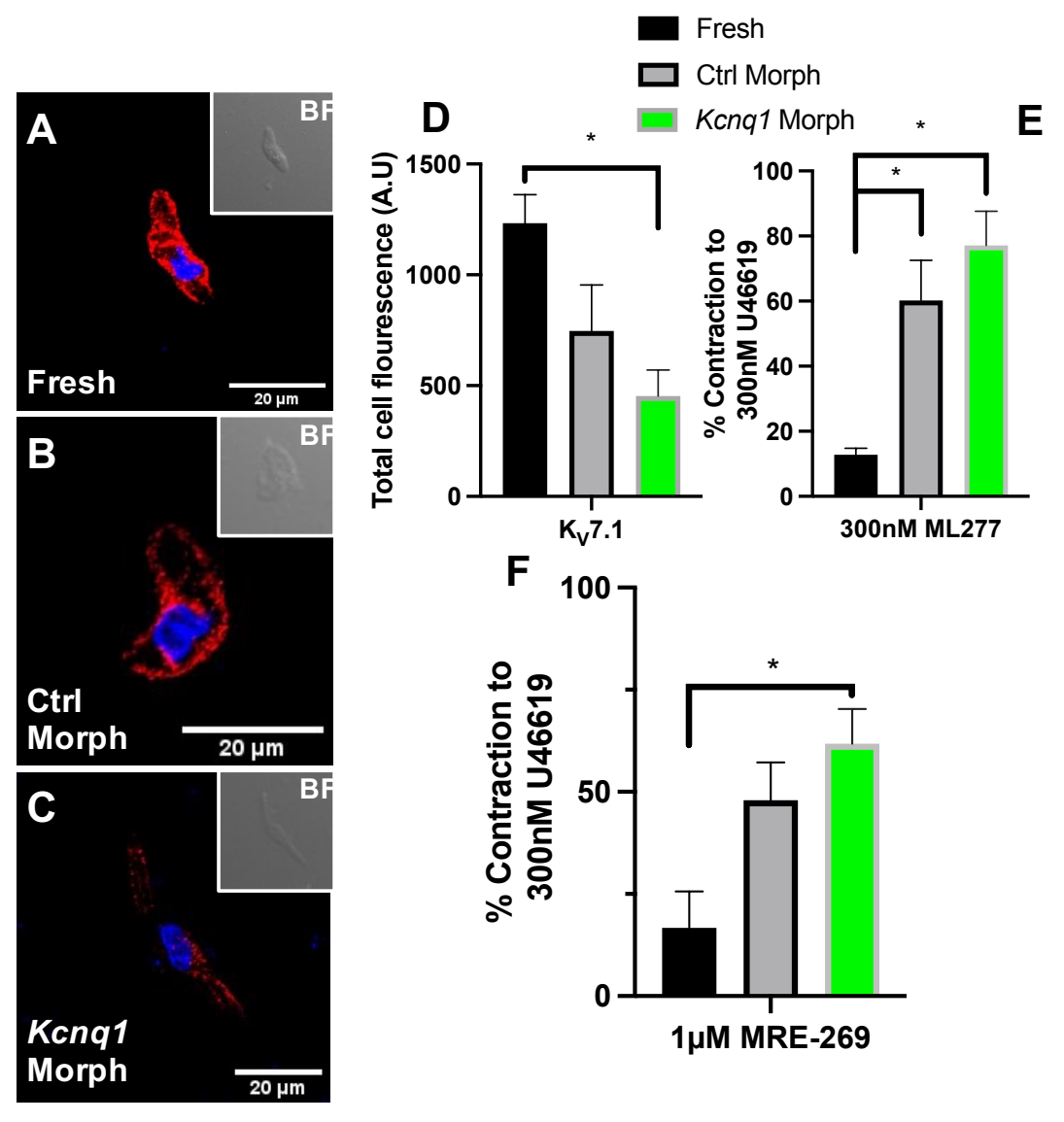



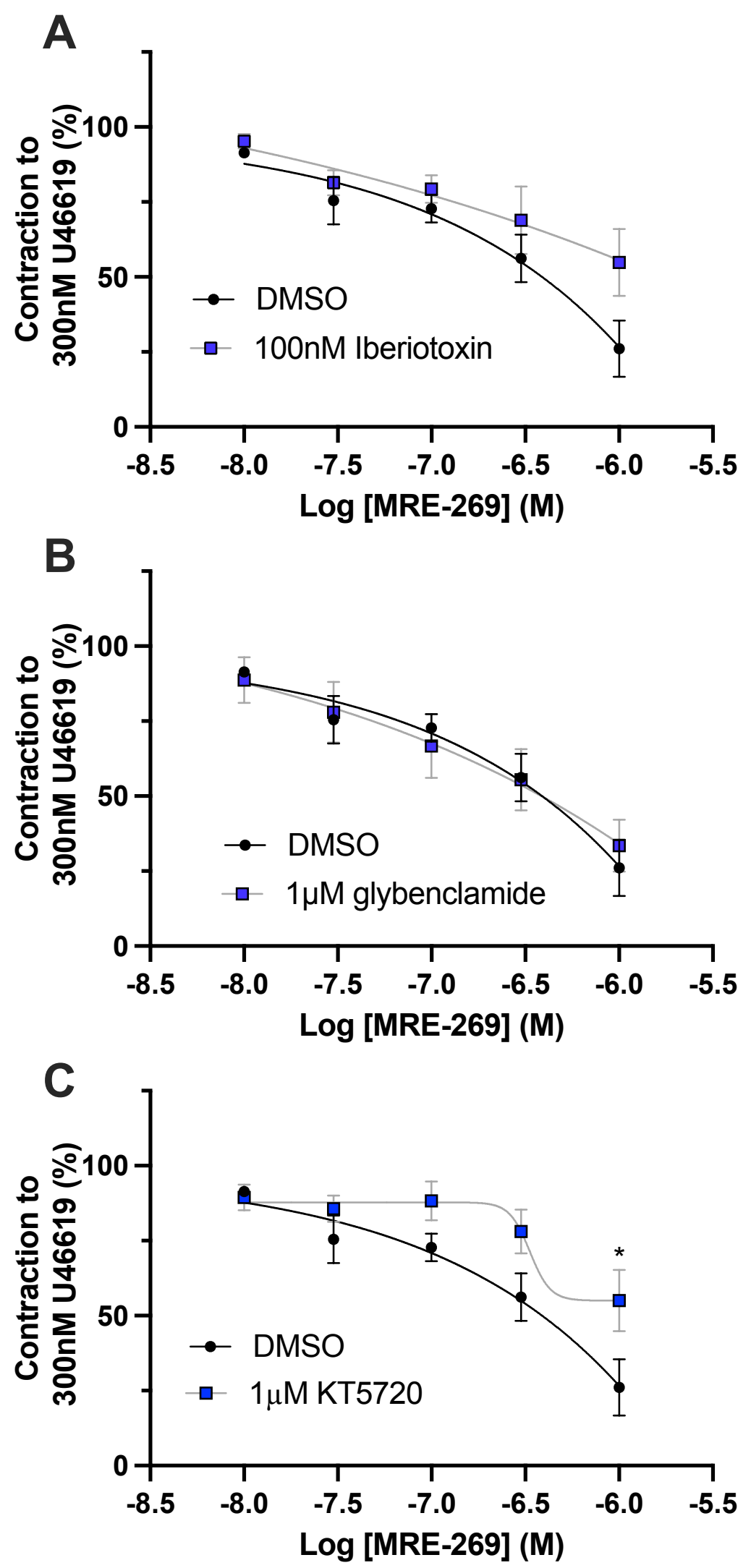

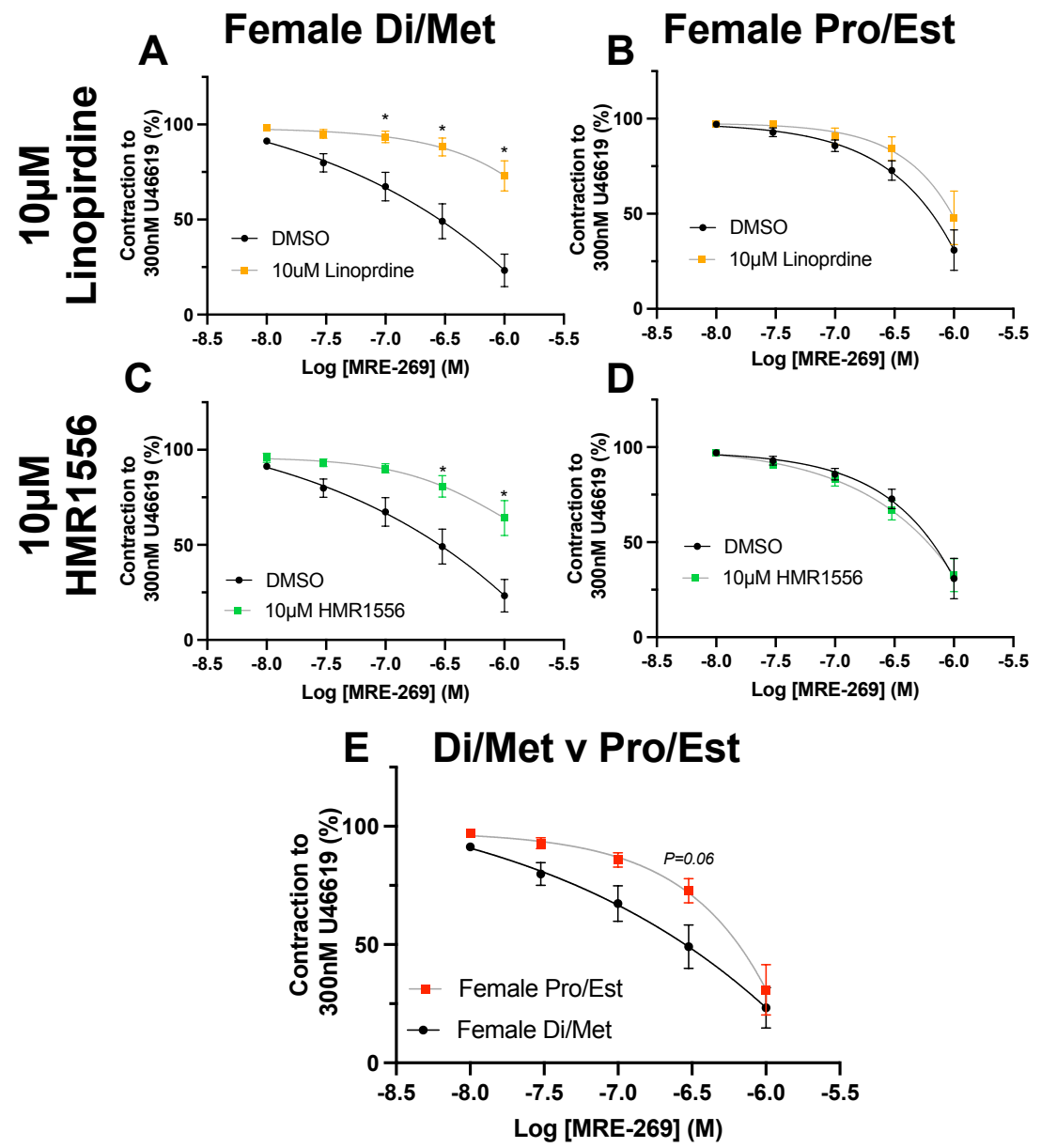